\title{
MARCAS LINGUÍSTICAS NORDESTINAS PRESENTES NA OBRA MORTE E VIDA SEVERINA, DE JOÃO CABRAL DE MELO NETO: análise das designações
}

\author{
Northeastern linguistic marks present in the Morte e Vida Severina, of João Cabral de \\ Melo Neto: analysis of designations
}

\author{
Daniel dos Santos Teixeira ${ }^{1}$ \\ Safira Ravenne da Cunha Rêgo ${ }^{2}$
}

RESUMO: A personificação do sujeito através da linguagem é algo notório nos usuários de uma língua. No Brasil, existem várias formas de comportamentos linguísticos, seja por função de região, de classe social, de situações (formais e informais) e por período histórico. Neste trabalho, buscamos a utilização da variação por região para explicar e caracterizar o sujeito nordestino apresentado na obra Morte e Vida Severina, do autor João Cabral de Melo Neto. A escolha do texto da análise se deu pela abordagem da representação da difícil vida do retirante, o qual, mesmo diante de todos os desafios, persiste em suas lutas diárias. Logo, foram necessárias bases teóricas a partir dos conhecimentos da Linguística e da Sociolinguística. Em favor disso, utilizamos, como referencial, Saussure (2006), Mollica; Braga (2015); além de Guimarães (2014), com a Semântica do Acontecimento, no que diz respeito às "Designações". Objetivamos evidenciar as questões de como a linguagem molda o seu usuário, através de suas próprias falas, discorrendo, portanto, sobre a análise sociolinguística, buscando aliar a linguística com as marcas de falares que se encontram como designações na obra popular da região nordeste, Morte e Vida Severina.

Palavras-chave: Sociolinguística. Variação. Designações. Caracterização. Morte e Vida Severina.

ABSTRACT: The personification of the subject through language is something notorious in the users of a language. In Brazil, there are several forms of linguistic behavior, either by function of region, social class, situations (formal and informal) and by historical period. In this work, we seek the use of variation by region to explain and characterize the Northeastern subject presented in the work Morte $e$ Vida Severina, by author João Cabral de Melo Neto. The choice of the text of the analysis was based on the representation of the difficult life of the retreatant, who,

\footnotetext{
1 Graduando em Letras - Língua Portuguesa e Literaturas de Língua Portuguesa pela Universidade Estadual do Maranhão (UEMA). E-mail: danieldst81@gmail.com

${ }^{2}$ Graduada em Letras - Português (UFPI). Especialista em Docência do Ensino Superior (ISEPRO). Mestre em Letras - Estudos da Linguagem (UFPI). Professora efetiva da educação básica da SEDUC-MA. Professora substituta da Universidade Estadual do Maranhão (UEMA). E-mail: saffira01@hotmail.com
}

Cadernos Cajuína, V. 4, N. 1, 2019, p.194- 207.

ISSN: 2448-0916 
even in the face of all challenges, persists in his daily struggles. Therefore, theoretical bases were necessary from the knowledge of Linguistics and Sociolinguistics. In favor of this, we use, as reference, Saussure (2006), Mollica; Braga (2015); in addition to Guimarães (2014), with the Semantics of the Event, with regard to the "Designations". We aim to highlight the questions of how the language shapes its user, through its own lines, and discusses, therefore, the sociolinguistic analysis, seeking to combine linguistics with the dialects that are as designations in the popular work of the northeast region, Morte and Vida Severina.

Keywords: Sociolinguistic. Variation. Designations. Characterize. Morte e Vida Severina.

\section{QUESTÕES INICIAIS}

As cadeias que envolvem as estruturas de gramática, língua e seu funcionamento possuem variadas vertentes de estudo e muitas características com altas diversidades. Pensar em todos esses estudos é passear por diferentes ciências e formas de se fazer e reinventar a própria língua, inclusive, elencando questões voltadas para a produção da fala em fonética e fonologia, como também, questões da produção da representação da fala no papel. Mas, pensar assim, seria considerar, desde os escritos científicos até os literários. Por isso, restringimos nosso estudo para os comportamentos acerca da Linguística, enquanto ferramenta que busca a própria explicação dos fenômenos em torno da produção da linguagem.

Discorrer sobre esta ciência é considerar um arcabouço de teóricos e teorias. Versaremos, neste trabalho, acerca dos estudos de língua de Saussure (2006), e, para as questões sociais que englobam a Linguística, utilizamos a autores que pesquisam a Sociolinguística, tais como por Mollica; Braga (2015).

Para delimitar nosso objeto de estudo, a Sociolinguística, e para esta se fazer, apresentamos a composição poética Morte e Vida Severina, do autor modernista João Cabral de Melo Neto, na qual se realizou uma busca teórica em torno dos personagens, versando pela caracterização do nordestino, realizando-se, portanto, um estudo semântico em torno das "designações", com base em Eduardo Guimarães (2014). Com isso, buscamos a compreensão, através da análise sociolinguística e semântica, dos fenômenos escritos que representam os falares nordestinos e como estes representam a população dessa região. 
Fizemos um percurso social da obra de Melo Neto, na qual constam os detalhes que constituem o seu espaço literário, acrescentando a isso, os acontecimentos juntamente com outras obras que tratam da mesma temática: a realidade nordestina. Para tal, através dos estudos sociolinguísticos, foi organizado, com base na obra-poema, um tópico deste estudo, com traços escritos variacionais da obra, os quais se mostram muito presentes, no que tange à caracterização do nordestino. Os estudos da Sociolinguística Variacionista de Mollica; Braga (2015) são a bússola para os conceitos de variações, que restringem os caminhos por onde perpassa nossa análise.

Ainda, foi necessária a apropriação dos estudos semânticos, ao que utilizamos Guimarães (2014) e sua "Semântica do Acontecimento", e as designações, entendendo que "designar é, logo, uma tarefa de estabelecimento de sentidos e significações" (RÊGO, 2016, p. 55).

Pretendemos, pois, nesse artigo, evidenciar como as falas circulam no território nordestino. Iniciamos com as falas características do nordeste presentes na obra. Analisamos, de início, com as variações nela presentes e, depois, como as variações caracterizam o ser resistente do nordeste, enquanto marcado por suas expressões típica, as designações. Por fim, estabelecemos os traços linguísticos que caracterizam o personagem protagonista, como sendo sua própria designação, ressaltando que esta estabelece com o seu meio questões em torno dos sentidos.

\section{PRESSUPOSTOS TEÓRICOS}

Os estudos referentes a espaço, sociedade e linguagem buscam explicar a dinâmica social existente na língua. As questões dos estudos linguísticos, tão importantes no cenário atual, por meio das quais constantes evoluções na língua se tornam cada vez mais frequentes, surgem apenas no século XX, com Ferdinand de Saussure, considerado o pai da Linguística moderna, com estatuto de ciência.

Em seu trabalho, o Curso de Linguística Geral (obra póstuma), Saussure (2006) exemplifica o quão dinâmica, mutável e maleável é nosso sistema de comunicação. Para Saussure (2006, p. 13), a linguística ocupa-se de:

a) Fazer a descrição e a história de todas as línguas que puder abranger o que quer dizer: fazer a história das famílias de línguas e 
reconstituir, na medida do possível, as línguas-mães de cada família;

b) Procurar as forças que estão em jogo, de modo permanente e universal, em todas as línguas e deduzir as leis gerais às quais se possam referir todos os fenômenos peculiares da história; c) Delimitar-se a definir-se a si própria.

Dessa maneira, seria a Linguística, a ciência concebida por Saussure, a resposta (saída) aos incansáveis questionamentos do funcionamento e existência da língua(gem). Discorremos neste estudo, sobre os procedimentos teóricosmetodológicos que condizem com a relação entre Linguística e os espaços sociais, mais especificamente, tratando-se da própria variação existente nos falares na obra Morte e Vida Severina, de João Cabral de Melo Neto.

Falemos, pois, da Sociolinguística que, segundo Mollica; Braga (2015), estuda a língua em uso no seio das comunidades de fala, voltando a atenção para algum tipo de investigação que correlaciona aspectos linguísticos e sociais. Transcorremos sobre a própria variação linguística. Mollica; Braga (2015, p. 10) ressaltam que ela:

Constitui fenômeno universal e pressupõe a existência das formas linguísticas alternativas denominas variantes. Entendemos então por variantes as diversas formas alternativas que configurem um fenômeno variável, tecnicamente chamado de variável dependente.

Dessa maneira, entendemos a Linguística como uma ciência maior e a Sociolinguística como uma das ramificações da primeira, sendo que "a linguística volta-se para todas as comunidades com o mesmo interesse científico e a sociolinguística considera a importância social da linguagem, dos pequenos grupos socioculturais a comunidade maiores" (MOLLICA; BRAGA, 2015, p. 10).

Pelos estudos da Sociolinguística, compreendemos as variações existentes em uma língua, ressaltando que na Língua Portuguesa Brasileira os estudos se dão, como nas demais línguas, em todas as vertentes, pois, encontramos "fatores de natureza fonomorfossintatáticos, os semânticos, os discursos e os lexicais" (MOLLICA; BRAGA, 2015, p. 11). Buscam-se, então, em estudos de variações as mais diversas formas e contexto, desde a enunciação à escrita.

Nesse sentido, compreendemos que o sujeito é resultado das formas como fala, dependendo do seu meio social, tendo sua autoafirmação enquanto sujeito 
pertencente a uma referente camada social, de acordo com suas variações mais presentes, ou seja, como ele se comporta e o que faz do seu vocabulário.

\title{
2.1 Variação e designação
}

As variações linguísticas fazem parte dos usos cotidianos da língua. Em questões de estudo sobre variações e designações, compreendemos que essas variações são interpeladas pelos seus utilizadores. Dessa maneira, segundo Guimarães (2014, p. 60):

\begin{abstract}
A designação é o sentido de um nome que estabelece a relação desse nome com as coisas tomadas como existentes, mas esta relação não é referencial. Trata-se de um processo pelo qual os nomes identificam aquilo sobre o que falam. A linguagem, nessa medida, produz uma 'partilha do real'. A designação identifica o existente (físico ou não) de algum modo, e essa é relação que tem com ele, a qual, inclusive, possibilita que se faça referência a coisas particulares em situações particulares.
\end{abstract}

Trabalhamos as designações a partir das variações como uma ferramenta que direciona os nomes referentes ao nordestino e ao ambiente que o circula. Para isso, estabelecemos uma questão de continuidade sobre o que são as variações, concebendo, pois, a relação contínua dos nomes com seus significados existentes.

Desse modo, nosso estudo constitui-se de uma breve análise sóciosemântica-linguística dos aspectos que consideramos relevantes para a construção da imagem do nordestino presente na obra analisada.

\section{MORTE E VIDA SEVERINA, DE MELO NETO: UMA ANÁLISE SOCIAL}

João Cabral de Melo Neto nasce em Recife (PE) em janeiro de 1920, tendo findando sua vida em outubro de 1999 no Rio de Janeiro (RJ). Conhecido com um dos poetas mais importantes de sua época, Melo Neto tem suas representações literárias compostas por composições que visam a estética da obra em todos os seus vieses, escrevendo com temáticas voltadas principalmente, para problemáticas sociais no nordeste brasileiro.

Morte e Vida Severina é uma composição poética regionalista publicada em 1955, sendo considerado modernista. Com fortes marcas do lirismo, por apresentar 
marcas sentimentais e com a maioria do texto em primeira pessoa, o poema ainda conta com, em algumas situações, presença do gênero dramático.

A produção está inserida na terceira fase do Modernismo, mais especificamente, na geração de 1945. Melo Neto está ao lado de grandes e renomados nomes da Literatura, como Guimarães Rosa, Clarice Lispector, Ariano Suassuna, dentre outros. Ao definir a produção do autor, Alfredo Bosi (2013) referese como "de alto padrão" a poesia de Melo Neto.

Retratando a seca, a fome e a miséria do estado de Pernambuco, que se mostra pobre e sem produções que possam sustentar a vida para maioria, o personagem principal, Severino, migra até o litoral, onde tem certeza que dias melhores lhe aguardam. Severino é um personagem como tantos outros, que busca a sobrevivência e que foge até a capital do estado

A produção de João Cabral de Melo Neto é um marco da literatura brasileira, apresentando-se hoje, com fortes produções do que tange à morte e vida do sujeito nordestino. Tendo várias publicações, adaptações ao cinema, obra disponível online em forma de PDF, e até mesmo, uma HQ produzida, o autor descreve como é a vida de quem migra em busca de melhores questões de vida e, através desse caminho, acaba conhecendo outros sujeitos com história e trajetória de vida semelhante.

Destacar essa poesia e a compor como objeto desse estudo é, além de tudo, ressaltar que não apenas ela traz perceptivas da vida na região do nordeste brasileiro, como também aborda os problemas sociais que englobam esse cenário.

Tais características da obra podem ser evidenciadas em muitas outras produções acerca do nordeste, como por exemplo, Vida Secas, publicada em 1938, de Graciliano Ramos, romancista, cronista, jornalista, dentre outras profissões. Nesta obra, o autor retrata a fuga da seca de Fabiano e sua família em companhia da cachorra Baleia, em busca de novos locais para produzir e trabalhar.

Fabiano, Sinhá Vitoria, os dois filhos do casal e a cachorra Baleia encontram-se também, como retirantes que, logo em seguida, conseguem achar um local onde pensam que a vida será melhor. Porém, a condição de 'retirar' persiste em marcar a família e, mais uma vez, esta volta à estrada e à persistente procura de uma melhor localidade. As descrições de Ramos, ao escrever sobre a família de Fabiano, são tamanhas e tão fidedignas, que compreendemos o sofrimento como algo que marca o próprio Nordeste. 
Outras possíveis interpretações das situações do espaço nordestino são possíveis através da obra de arte Retirantes, de Candido Portinari. Trata-se de um óleo sobre tela, pintado no estado do Rio de Janeiro. Nela, podem-se perceber as reais condições de como se propagam as vida dos moradores à margem da população no nordeste brasileiro.

Figura 1: Quadro "Os Retirantes” de Cândido Portinari, óleo sobre tela

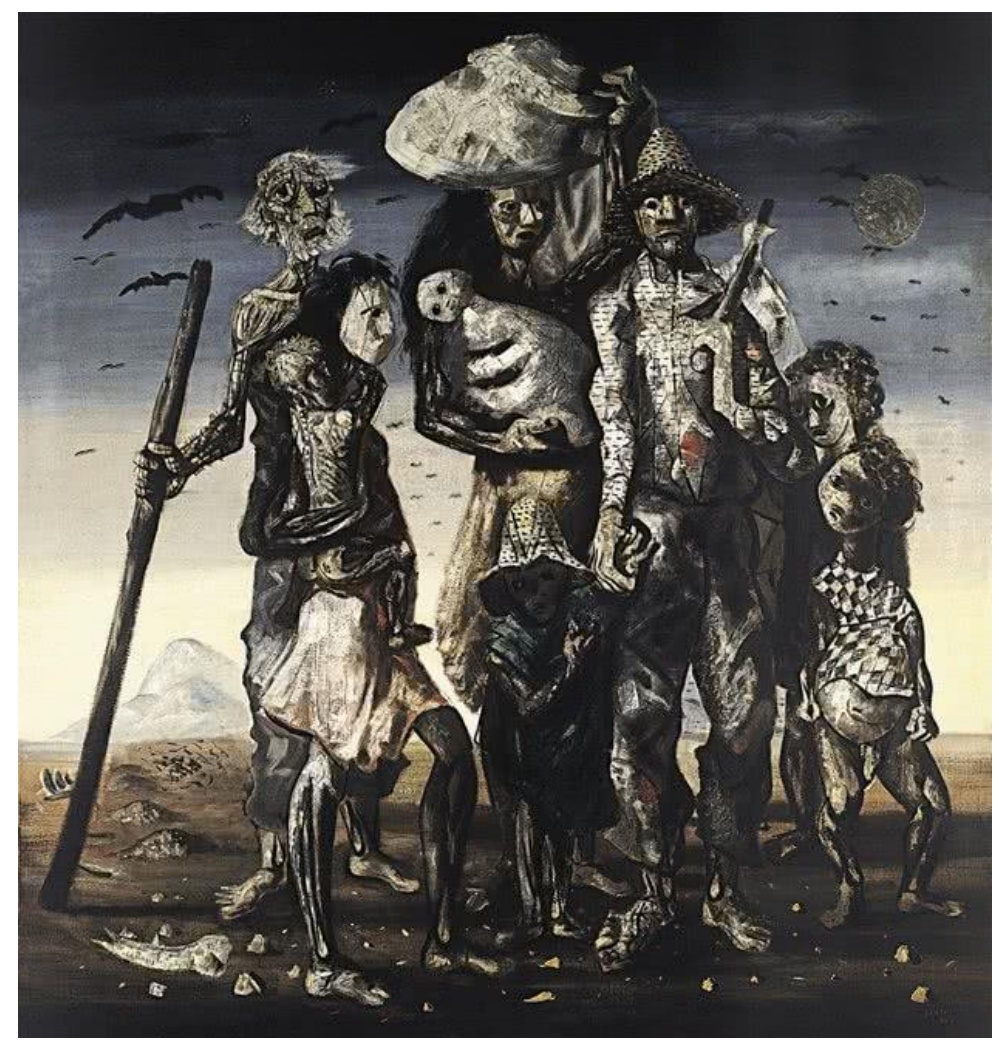

Fonte: $<$ https://www.culturagenial.com/quadro-retirantes-de-candido-portinari/ >. Acesso em: 20 out. 2018.

Vemos nesta obra, o retrato de uma família de retirantes, com roupas esfarrapadas, com marcas de desnutrição e suas poucas bagagens em busca de melhores lugares para habitação. Através destas interpretações, compreendemos que as figuras dos problemas existentes no nordeste brasileiro, por mais que se diferenciem em suas abordagens, seguem quase que as mesmas constituídas pela luta contínua do nordestino. Dessa forma, evidenciamos algumas questões implícitas nas construções de suas linguagens.

\section{SUJEITO NORDESTINO E SUAS DESIGNAÇÕES}


A personificação do sujeito nordestino através da fala ainda é rodeada de diversos paradigmas e tabus. $O$ preconceito que cerca o sujeito em decorrência de sua fala, nesse caso, com marcas regionalistas, ainda contribui com as demasiadas desigualdades que moldam e exigem a criação de personalidades igualitárias para toda uma população de uma determinada localidade.

Dessa forma, a criação de diversas imagens acerca de como a linguagem é criada, recriada e difundida no Nordeste traz à tona as questões dos preconceitos que giram em torno do falante nordestino.

Construímos, então, algumas das marcas de linguagem que são consideradas variações e/ou costumeiras no nordeste, buscando exemplificar quais são as expressões mais rotineiras no território nordestino e o que elas significam. Diante disso, trabalhamos as designações existentes no texto, segundo Guimarães (2014).

Iniciamos nossa análise com a apresentação do sujeito Severino, que se dá no início da poesia de Melo Neto (2000, p. 45):

- O meu nome é Severino, como não tenho outro de pia. Como há muitos Severinos, que é santo de romaria, deram então de me chamar Severino de Maria; como há muitos Severinos com mães chamadas Maria, fiquei sendo o da Maria do finado Zacarias. Mais isso ainda diz pouco: há muitos na freguesia, por causa de um coronel que se chamou Zacarias e que foi o mais antigo senhor desta sesmaria.

O autor apresenta Severino como só mais um dos tantos outros que existem. Dá-se um nome comum no nordeste brasileiro ao protagonista, assim como o de sua mãe (Maria). Após, verifica-se também, a personificação do sujeito ainda comum, pois o senhor das sesmarias que existiu naquela região é também, um adjetivo atribuído a outros tantos Severinos. Nota-se ainda, a utilização do vocábulo sesmaria, que no texto remonta a algum lote de terra abandonada.

O narrador-personagem continua e, dessa vez, compara-se com outros que são iguais a si. Diz Severino que:

Somos muitos Severinos iguais em tudo na vida: na mesma cabeça grande que a custo é que se equilibra, no mesmo ventre crescido sobre as mesmas pernas finas e iguais também porque o sangue, que usamos tem pouca tinta. (MELO NETO, 2000, p. 46) 
As características que ele mesmo the atribui no texto referem à imagem estigmatizada as quais todos os nordestinos são vinculados no resto do país. Em sua fala, apresenta-se como um sujeito com cabeça grande, pernas finas, com sangue com pouca cor, em decorrência de sua própria existência, enquanto não pertencente à classe mais alta. Destaca-se, assim, a utilização de uma linguagem simples, coloquial e de fácil entendimento, presente em todo o decorrer da narração.

Ainda, nessa primeira parte do texto, Severino atribui à imagem que todos os seus iguais estão confinados a viver a mesma linha de vida, exemplificados pela utilização de "sina" em "Somos muitos Severinos, iguais em tudo e em sina" (MELO NETO, 2000, p. 2), em que sina significa destino.

Logo após, Severino encontra com mais dois iguais e um diálogo se inicia:

- A quem estais carregando, irmão das almas, embrulhado nesta rede? Dizei que eu saiba. - A um defunto de nada, irmão das almas, que há muitas horas viaja à sua morada. E sabeis quem ele era, irmão das almas, ou se chamava? Severino Lavrador, irmão das almas, mas já não lavra. (MELO NETO, 2000, p. 47)

Além da própria designação "irmão das almas", que remete a um tratamento religioso, pois no nordeste a fé católica costuma ser de grande força, notamos as expressões "estais" e "sabeis", marcas linguísticas contínuas dos nordestino, cujos verbos estão em $2^{\mathrm{a}}$ pessoa do plural do presente do indicativo. Também é típico da região, a caracterização do defunto enquanto vivo ser chamado de "Severino Lavrador", considerando a própria atividade lavrar ser uma das profissões a que, na maior parte das vezes, os nordestinos estão confinados.

O diálogo continua e, dessa vez, o motivo da morte é indagado:

- E foi morrida essa morte, irmão das almas, essa morte foi morrida ou foi matada? - Até que não foi morrida, irmão das almas, essa foi morte matada, numa emboscada. - E o que guardava a emboscada, irmão das almas e com o que foi que mataram, com faca ou com bala? - Este foi morto à bala, irmão das almas, mas garantindo é bala, mais longe vara. (MELO NETO, 2000, p. 47-48)

Refere-se "morte morrida" a de causas naturais, e "matada", a morte causada por outros homens. "Longe vara" remete ao sentindo de maior campo de alcance. Em todos os momentos, além disso, o personagem se adequa como um 
retirante, ou seja, "aquele que se desloca de um lugar para outro em busca de trabalho ou melhores condições para viver" (RÊGO, 2016, p. 64).

Dá-se continuidade com:

- E o que havia ele feito irmãos das almas, e o que havia ele feito contra a tal pássara? - Ter um hectare de terra, irmão das almas, de pedra e areia lavada que cultivava. - Mas que roças que ele tinha irmãos das almas que podia ele plantar na pedra avara? - Nos magros lábios de areia, irmão das almas, os intervalos das pedras, plantava palha. - E era grande sua lavoura, irmãos das almas, lavoura de muitas covas, tão cobiçada? - Tinha somente dez quadras, irmão das almas, todas nos ombros da serra, nenhuma várzea. - Mas então por que o mataram, irmãos das almas, mas então por que o mataram com espingarda? - Queria mais espalharse, irmão das almas, queria voar mais livre essa ave-bala. - E agora o que passará, irmãos das almas, o que é que acontecerá contra a espingarda? - Mais campo tem para soltar, irmão das almas, tem mais onde fazer voar as filhas-bala. (MELO NETO, 2000, p. 48-49)

As expressões "pedra avara", "nos magros lábios da areia" e "ombros da serra nenhuma várzea" fazem referência ao solo infértil, caracterizando assim, a vegetação rasteira, com baixa umidade e poucos nutrientes na terra para o plantio típico nordestino. Sua jornada avança e, dessa vez, vemos o seguinte:

- Antes de sair de casa aprendi a ladainha das vilas que vou passar na minha longa descida. Sei que há muitas vilas grandes, cidades que elas são ditas; sei que há simples arruados, sei que há vilas pequeninas, todas formando um rosário cujas contas fossem vilas, de que a estrada fosse a linha. Devo rezar tal rosário até o mar onde termina, saltando de conta em conta, passando de vila em vila. Vejo agora: não é fácil seguir essa ladainha; entre uma conta e outra conta, entre uma e outra ave-maria. (MELO NETO, 2000, p. 50 - 51)

"Ladainha" aqui se encontra como sinônimo de história. E, novamente, o catolicismo aparece no texto quando do autor transparece a fé de Severino ao "rezar tal rosário e outra ave-maria", orações de praxe católica. Presenciamos, mais uma vez, os costumes católicos com a utilização de "Os demônios te atalharem, Mais a Virgem da Conceição" e "Duas excelências", quando a "na casa que o retirante chega estão cantando excelências para um defunto" (MELO NETO, 2000, p. 52):

- Finado Severino, quando passares em Jordão e os demônios te atalharem perguntando o que é que levas... - Dize que levas cera, capuz e cordão mais a Virgem da Conceição. - Finado Severino, 
etc... - Dize que levas somente coisas de não: fome, sede, privação. - Finado Severino, etc... - Dize que coisas de não, ocas, leves: como o caixão, que ainda deves. - Uma excelência dizendo que a hora é hora. - Ajunta os carregadores que o corpo quer ir embora. - Duas excelências... -...dizendo é a hora da plantação. Ajunta os carreadores... -... que a terra vai colher a mão. (MELO NETO, 2000, p. 52)

A jornada continua. Dessa vez, o retirante avista uma senhora na janela e uma nova conversa tem início:

- Muito bom dia, senhora, que nessa janela está; algum trabalho encontrar? - Trabalho aqui nunca falta a quem sabe trabalhar; o que fazia o compadre na sua terra de lá? - Pois fui sempre lavrador, lavrador de terra má; não há espécie de terra que eu não possa cultivar. - Isso aqui de nada adianta, pouco existe o que lavrar; mas diga-me, retirante, o que mais fazia por lá? - Também lá na minha terra de terra mesmo pouco há; mas até a calva da pedra sinto-me capaz de arar. - Também de pouco adianta, nem pedra há aqui que amassar; diga-me ainda, compadre, que mais fazias por lá? Conheço todas as roças que nesta chã podem dar; o algodão, a mamona, a pita, o milho, o caroá. - Esses roçados o banco já não quer financiar; mas diga-me, retirante, o que mais fazia lá? - Melhor do que eu ninguém sei combater, quiçá, tanta planta de rapina que tenho visto por cá. - Essas plantas de rapina são tudo o que a terra dá; diga-me ainda, compadre que mais fazia por lá? - Tirei mandioca de chãs que o vento vive a esfolar e de outras escalavras pela seca faca solar. - Isto aqui não é Vitória nem é Glória do Goitá; e além da terra, me diga, que mais sabe trabalhar? (MELO NETO, 2000 , p. 54 - 55)

A utilização de "compadre" se constrói como um tratamento muito comum para ambos na conversa. Logo após, observamos terra má, que mais uma vez, se refere à infertilidade do solo. Nota-se também, a utilização de "retirante" pela senhora ao se referir a Severino, mostrando a qualidade daquele que se retira, que foge em busca algo novo.

Em continuidade, a utilização de "algodão", "mamona", "pita", "milho" e "coroá" remetem a produtos muito produzidos no Nordeste em tempos de fartura. Também, "quiçá", “urtigas" e "planta de rapina”, como plantas que crescem em meio à seca e são consideradas ervas daninhas.

A senhora, em resposta a Severino, transparece que suas habilidades não Ihe bastam e que ele precisa ainda mais fazer para ali prosperar. 
Mas diga-me retirante, sabe benditos rezar? sabe cantar excelências, defuntos encomendar? sabe tirar ladainhas, sabe mortos enterrar? Já velei muitos defuntos, na serra é coisa vulgar; mas nunca aprendi as rezas, sei somente acompanhar. (MELO NETO, 2000, p. 56)

Compreendemos benditos como uma oração católica. Cantar excelências como música que se canta em rituais fúnebres de enterros. E defuntos encomendar, como a preparação do corpo para o enterro.

À frente, essa mesma senhora se apresenta como "rezadora titular" (MELO NETO, 2000, p. 11), ou seja, aquela que tem por profissão estar nos velórios para estabelecer todos os ritos necessários que a igreja católica estabelece. Já "doutor de anel no anular" (MELO NETO, 2010, p. 11) seria um médico de formação acadêmica e que utiliza o anel representando o curso de medicina.

Ao passo que Severino segue sua jornada, agora se encontra em meio a um enterro, o qual prossegue a assistir:

- Esta cova em que estás, com palmos de medida é a cota menor que tiraste em vida. - É de bom tamanho, nem largo nem fundo, é a parte que te cabe neste latifúndio. - Não é cova grande. É cova medida, é a terra que querias ver dividida. (MELO NETO, 2000, p. 59)

Além da clara repetição de palavras, como "cova" e "medida", presente em todo capítulo do poema, o que mostra a clara persistência do autor pela constante estética em seu poema, observamos a utilização do vocábulo "latifúndio", que remete a terra. No decorrer do texto, vemos também, a utilização de "saúvas", que remete a uma espécie de formigas típicas e predominantes no nordeste e, ainda, a expressão "homem de eito e trator" que traz sua significância a dono de uma extensão de terras e com plantações nestas, como é claro abaixo.

- Ai ficarás para sempre, livre do sol e da chuva, criando tua saúvas (...) - Trabalharás uma terra da qual, além de senhor, serás homem de eito e trator. (MELO NETO, 2000, p. 60)

A persistência do autor em demostrar as reais condições através de sua escrita, com grandes diversidades linguísticas no texto, deixa claro que as marcas linguísticas trazem a toma marcas dos falares populares no nordeste brasileiro. Para 
continuar nosso estudo, traçamos uma tabela com as demais designações presentes no texto.

Quadro 1: Representação de designações e seus sentindo presente nos últimos capítulos do poema Morte e Vida Severina de Melo Neto

\begin{tabular}{|l|l|}
\hline \multicolumn{1}{|c|}{$\begin{array}{c}\text { DESIGNAÇÃO } \\
\text { Cariação ou expressão linguística) }\end{array}$} & \multicolumn{1}{c|}{\begin{tabular}{c}
\multicolumn{1}{c|}{ SENTINDO } \\
(Significado correspondente à variação)
\end{tabular}} \\
\hline Xale (MELO NEOT, 2000, p. 61) & $\begin{array}{l}\text { Uma escavação em terra que chega a } \\
\text { lençóis freáticos rasos, dessa forma apenas } \\
\text { uma escavação rasa para se encontra } \\
\text { água. }\end{array}$ \\
\hline Cingida (MELO NETO, 2000, p. 61) & $\begin{array}{l}\text { Uma peça de finos panos que se coloca em } \\
\text { volta do pescoço. }\end{array}$ \\
\hline Rebolo (MELO NETO, 2000, p. 61) & No sentindo de bem costurado. \\
\hline Fadiga (MELO NETO, 2000, p. 63) & Objeto que se joga em algo ou alguém. \\
\hline $\begin{array}{l}\text { Comboio de alguém (MELO NETO, 2000, p. } \\
\text { 65) }\end{array}$ & Em companhia de uma pessoa. \\
\hline Estrovengas (MELO NETO, 2000, p. 69) & Algo complicado de se realizar. \\
\hline Mestre Carpina (MELO NETO, 2000, p. 70) & $\begin{array}{l}\text { Senhor residente de Carpina (Cidade de } \\
\text { Pernambuco) com idade avançado e com } \\
\text { grandes conhecimentos. }\end{array}$ \\
\hline
\end{tabular}

Fonte: Elaborado pelos autores

Avaliamos então, que a forma de escrito de Melo Neto preserva a estética, elenca e transcreve as variações dos falares nordestinos. A análise das designações nos permite observar como a funcionalidade da língua transforma os seus cenários e usuários através dos falares, mesmo que estes sejam escritos.

\section{ALGUMAS CONSIDERAÇÕES}

Através do percurso social da obra de Melo Neto, aqui estudada, percebemos algumas das reais condições nordestinas, que submetem seus moradores a se tornarem migrantes em busca de trabalho, dignidade e uma vida melhor. Ainda, observamos que as problemáticas sociais de Morte e Vida Severina 
são trabalhadas também em outras obras, como, por exemplo, Vidas Secas, de Graciliano Ramos, nas quais observamos os mesmos traços; e, na própria arte, como em: Os Retirantes, quadro de Portinari. A maioria das obras de Melo Neto expõem a condição do nordeste frente aos problemas sociais, em um Brasil que elitiza uma minoria e marginaliza o restante.

Neste trabalho, fizemos um percurso das designações nordestinas presentes na obra utilizada. Percebemos, pois, que as designações presentes não são apenas vocábulos comuns escritos, mas constituem variações regionais, em todo o texto, o que se tornou mais viável ao nos apropriarmos dos estudos sociolinguísticos e semânticos. Para nossa análise propriamente dita, estabelecemos uma proposta de verbetes com seus significados, utilizando algumas das variações linguísticas presentes na obra, que marcam o trabalho de Melo Neto.

\section{REFERÊNCIAS}

BOSI, Alfredo. História concisa da literatura brasileira. 49. ed. São Paulo: Cultrix, 2013.

GUIMARÃES, Eduardo. Espaço de enunciação, cena enunciativa, designação. Laboratório Corpus: Universidade Federal de Santa Maria - UFSM, Jan./Mar 2014.

MELO NETO, João Cabral de. Morte e vida Severina e outros poemas para vozes. 4. ed. Rio de Janeiro: Nova Fronteira, 2000.

MOLLICA, Maria Cecilia; BRAGA, Maria Luiza (Orgs.). Introdução à

Sociolinguística: o tratamento da variação. 4. ed. São Paulo: Contexto, 2015.

RÊGO, Safira Ravenne da Cunha. Teodoro Bicanca, de Renato Castelo Branco: da produção de sentidos e da construção da imagem do homem nordestino. 2016. 88 f. Dissertação (Mestrado em Letras - Estudos de Linguagem) - Centro de Ciências Humanas e Letras. Universidade Federal do Piauí, Teresina, 2016.

SAUSSURE, Ferdinand de. Curso de Linguística Geral. 27. Ed. São Paulo: Cultrix, 2006. 